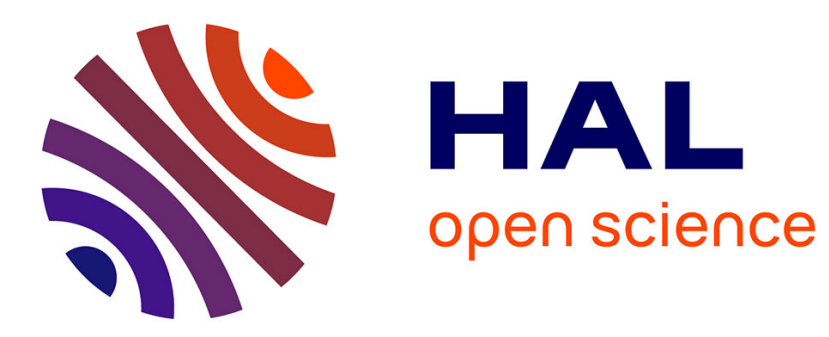

\title{
Role of multidrug resistance in glioblastoma chemoresistance: Focus on ABC transporters
}

Mohammed Ahmed, Maite Verreault, Xavier Declèves, Ahmed Idbaih

\section{To cite this version:}

Mohammed Ahmed, Maite Verreault, Xavier Declèves, Ahmed Idbaih. Role of multidrug resistance in glioblastoma chemoresistance: Focus on ABC transporters. Ramasamy Paulmurugan; Tarik F. Massoud. Glioblastoma Resistance to Chemotherapy: Molecular Mechanisms and Innovative Reversal Strategies, 15, Elsevier, pp.243-261, 2021, Cancer Sensitizing Agents for Chemotherapy, 978-0-12821567-8. 10.1016/B978-0-12-821567-8.00025-7 . hal-03499072

\section{HAL Id: hal-03499072 https://hal.sorbonne-universite.fr/hal-03499072}

Submitted on 19 Jan 2022

HAL is a multi-disciplinary open access archive for the deposit and dissemination of scientific research documents, whether they are published or not. The documents may come from teaching and research institutions in France or abroad, or from public or private research centers.
L'archive ouverte pluridisciplinaire HAL, est destinée au dépôt et à la diffusion de documents scientifiques de niveau recherche, publiés ou non, émanant des établissements d'enseignement et de recherche français ou étrangers, des laboratoires publics ou privés. 


\title{
Role of Multi-Drug Resistance in Glioblastoma Chemoresistance: Focus on ABC Transporters
}

Mohammed Ahmed ${ }^{\mathbf{1}, \mathbf{2}}$, Maite Verreault ${ }^{1}$, Xavier Declaeves ${ }^{3,4}$, Ahmed Idbaih $^{5}$

\author{
${ }^{1}$ Sorbonne Université, Institut du Cerveau - Paris Brain Institute - ICM, Inserm, CNRS, \\ APHP, Hôpital de la Pitié Salpêtrière, Paris, France \\ ${ }^{2}$ Faculté de Médecine Paris-Sud - Université Paris-Saclay, 91190, Saint-Aubin, France. \\ ${ }^{3}$ Inserm, UMR-S 1144, Université Paris Descartes - Paris Diderot, Variabilité de Réponse \\ Aux Psychotropes, Paris, F-75006, France. \\ ${ }^{4}$ Biologie du Médicament et Toxicologie, Hôpital Cochin, Assistance Publique-Hôpitaux \\ de Paris, Paris, F-75014, France. \\ ${ }^{5}$ Sorbonne Université, Institut du Cerveau - Paris Brain Institute - ICM, Inserm, CNRS, AP- \\ HP, Hôpital de la Pitié Salpêtrière, DMU Neurosciences, Service de Neurologie 2-Mazarin, \\ F-75013, Paris, France
}

\section{Corresponding author}

Ahmed Idbaih. Department of Neurology 2-Mazarin, Pitié-Salpêtrière University Hospital. 47-83, Boulevard de l'Hôpital, 75013 Paris, France. Tel : 01-42-16-03-85. Fax : 01-42-1604-18. Email : ahmed.idbaih@psl.aphp.fr 


\begin{abstract}
Glioblastoma (GBM) is the most frequent and the most aggressive primary cancer of the brain in adults. Despite aggressive therapeutic interventions, the median overall survival is below 18 months after initial diagnosis. The current standard of care of newly diagnosed GBM includes concurrent administration of temozolomide (TMZ) and radiotherapy followed by adjuvant TMZ. Since 2005, TMZ remained the first-line chemotherapy in treating GBM patients with its ability to cross the blood-brain barrier. However, after initial efficacy, GBM cells acquire resistance to TMZ and other chemotherapeutic agents via multiple mechanisms, including the expression of ATPbinding cassette $(A B C)$ efflux proteins. These transporters are involved in normal physiological functions, i.e., physiological cholesterol transport and elimination of toxins, but also it plays a role in pathological conditions, i.e., chemotherapies drug resistance. In humans, each $A B C$ protein has specific tissue's locations and specific functions. In this review, we highlight the role of $A B C$ proteins superfamily members $A B C B 1, A B C C 1$ and ABCG2 in the resistance of GBM cells to chemotherapy.
\end{abstract}

Keywords: Glioblastoma, $\mathrm{ABC}$ transporters, multidrug resistance, chemotherapies, Pglycoprotein, the clinical role of $A B C$ proteins 


\section{Introduction}

Glioblastoma (GBM) is the most common and the deadliest primary brain cancer in adults with a median overall below 18 months after initial diagnosis (1). The current standard of care in newly diagnosed GBM patients, established in 2005, relies on concurrent administration of temozolomide (TMZ) and radiotherapy regimen followed by adjuvant TMZ alone (2). Despite remarkable efforts in the neuro-oncology field to develop new treatments, TMZ remains today the standard first-line chemotherapy in GBM patients 'treatment $(1,2)$. TMZ is an alkylating agent with a small molecular weight (194.15 g/mol) that readily passes the blood-brain barrier (BBB) (3).

The essential and complex organ, which is the human brain, is separated from the BBB's blood. The BBB is a specificity of the central nervous system (CNS) blood vessels. The $\mathrm{BBB}$ isolates the brain from the blood for protection purposes (4). Indeed, it prevents potentially toxic molecules circulating in the bloodstream to access brain cells while ensuring the supply of nutrients to maintain homeostasis (5). Highly specialized brain capillary endothelial cells (ECs) form an essential part of the BBB. In addition to ECs, various cells contribute to the biophysical structure of BBB described in Figure 1. To date, five mechanisms are known to regulate the exchanges of molecules from blood to brain and vice versa. Passive diffusion of molecules through the BBB can occur paracellularly for very low molecular weight molecules (e.g., inorganic ions, water, gazes) and transcellularly for lipophilic compounds. An active transport can also occur either by : (i) transcytosis for some proteins (e.g., leptin, insulin, transferrin) or (ii) carrier-mediated proteins belonging to two major transporter superfamilies for small molecules. The solute carrier (SLC) superfamily contains more than 400 transporters that allow exchanges of small molecules through the BBB while ATP-binding cassette (ABC) transporters limit CNS penetration of small molecules by effluxing substrates from the brain ECs directly into the bloodstream (Figure 1) $(4,6,7)$. 
GBM cells acquire resistance to anticancer drugs via multiple mechanisms without being exhaustive: (i) acquisition of mutation in DNA repair genes, (ii) activation of alternative signalling pathways, (iii) immune escape, (iv) invasive switch from angiogenic growth and, (v) multidrug resistance mechanism (MDR) $(8,9)(10)$. MDR phenotype is observed in many types of cancers and induces: (i) increased efflux of drugs outside tumor cells and, (ii) reduced influx of drugs inside tumor cells (11). ABC transporters are efflux pump proteins involved in MDR. To date, 49 members of $A B C$ proteins have been identified to be involved in different biological mechanisms within the human body, and are classified in seven subfamilies; $A B C A$ (12 proteins), $A B C B$ (11 proteins), $A B C C$ (13 proteins), $A B C D$ (4 proteins), $A B C E$ (1 protein), $A B C F$ (3 proteins), and $A B C G$ (5 proteins) (12).

$A B C$ transporters are expressed in various tissues such as the liver and the intestine and have a distinct role in absorption, distribution, and excretion of drugs. Some $A B C$ transporters are predominantly expressed in ECs of the BBB (13). Indeed, $A B C B 1$ and $A B C G 2$ are expressed in $E C s$ of the $B B B$, while others (ABCC, $A B C G 2$ ) can be found in other cells such as astrocytes and neurons $(5,13,14)$. In humans, each $A B C$ protein is expressed in specific locations and exhibit specific functions. i.e. ABCA subfamily members are expressed mainly in the CNS while $A B C B$ subfamily members are mainly expressed in the BBB and liver (15). ABC proteins were studied in several types of cancers (16). In $G B M$, three proteins ( $A B C B 1, A B C C 1$ and $A B C G 2)$ were extensively studied and were shown to impact GBM cells biology. In this review, we highlight the role of $A B C$ protein family mainly $(A B C B 1, A B C C 1$ and $A B C G 2)$ in resistance of $G B M$ cells to chemotherapy.

\section{Structure and Functions of ABC Proteins}

\section{Structure of ABC Proteins}


The $\mathrm{BBB}$ was described for the first time in the $20^{\text {th }}$ century when an intravenous injection of Evans blue significantly stained all tissue except the CNS while a direct intrathecal injection could stain only the brain tissue. This staining pattern highlighted the possibility of a barrier, termed the $\mathrm{BBB}$, that prevents the dye to reach the brain tissue (4). The BBB's integrity is preserved throughout life to maintain homeostasis and regulate the influx and efflux of nutrients/metabolites between the blood and the brain (17). $A B C$ transporters, within the $B B B$, play a pivotal role in brain protection by eliminating harmful agents.

The $A B C$ transporters' primary function is to actively transport their substrates, ranging from low molecular weight molecules to polypeptides, outside cells. Despite the large number of $A B C$ transporters, they share structural similarities. In general, a typical $A B C$ protein includes two functional units called transmembrane domain (TMD) and nucleotide-binding domains (NBD) (Figure ). The NBDs are the ATPs binding units, and they contain the Walker A motif - a phosphate-binding structure-, Walker B motif, and Walker $\mathrm{C}$ motif. $\mathrm{C}$ motif is specific for $\mathrm{ABC}$ proteins while Walker $\mathrm{A}$ and $\mathrm{B}$ are present in all ATP dependent proteins. The TMDs include six or ten transmembrane helices depending on $A B C$ superfamily members. There are two types of transmembrane helices: the inward part (open to the cytoplasm) and the outward part (open to the extracellular environment). These helices determine the direction of transport of the $A B C$ transporters i.e. importer or exporter $(14,18)$.

\section{Functions of $A B C$ proteins}

Several physiological functions are reported for each $A B C$ subfamilies. However, $A B C$ proteins' main function is to actively transport cytotoxic xenobiotics and endobiotics against their concentration gradient (18). According to their location, they transport many substrates including anions, metal ions, peptides and lipophilic compounds (13). ABCA subfamily is mainly responsible for lipids and cholesterol 
transport while $A B C B, A B C C$ and $A B C G$ subfamily members are mainly associated with drug resistance and elimination of xenobiotics. Genetic variants in $A B C$ proteins are linked to genetic disorders e.g. a pathogenic variant in the $A B C D 2$ is responsible for $95 \%$ of cases of X-linked adrenoleukodystrophy (ALD) disorder(19). (Table ) summarizes the physiological functions of each $A B C$ subfamilies.

\section{Mechanisms of action of $A B C$ transporters}

$A B C$ proteins hydrolyze ATP to efflux chemical agents against their concentration gradient. The active transport cycle starts with binding a substrate, e.g. xenobiotic to a high-affinity structure formed by the TMDs and two ATP molecules binding NBDs. A conformational contribution forms the ATP binding sites at the NBDs residues from each NBD monomer. As a result, a conformational change in TMDs occurs from either outward to inward (importer) or vice versa (exporter) allowing the NBD units to form a dimer. The NBD dimer induces a major conformational change on the TMDs, allowing the xenobiotic to be translocated across the plasma membrane. The hydrolysis of ATP allows the NBD dimers to be dissociated and again inducing the TMDs conformational change, resulting in the xenobiotic to be released. A final step of restoration of the open NBD-dimer conformation then takes place (Figure 2) $(13,14,18,20,21)$.

\section{$A B C$ transporters in glioblastoma}

Our review used public data obtained from PubMed and Google Scholar. Original published articles were obtained using the keywords ( $A B C$ transporters, glioblastoma, TMZ, and chemotherapy). 151 articles appeared in the results from the search engines. Another step was carried out to exclude the duplicated and review articles. Following the removal of duplicated article and review articles, 91 abstracts were reviewed (abstract review), and only articles that studied $A B C$ transporters in glioblastoma were selected. Full texts were obtained for all 36 selected articles using access from https://universiteparissud.focus.universite-paris-saclay.fr/ and 
https://insermbiblio.inist.fr/ using personal access. (Figure ) summarizes the methodology used in the reviewing processes.

\section{ABCB1 (MDR1, P-Glycoprotein)}

ABCB1 which is also known as MDR1 and P-glycoprotein (P-GP) was identified by Victor Ling in 1976 (22) making it the first studied protein among all ABC proteins. $A B C B 1$ protein is a $170 \mathrm{kDa}$ glycoprotein highly expressed in endocrine tissues, liver, gallbladder and brain, and it is usually co-expressed with the ABCG2 protein (23). The physiological impact of ABCB1 protein was accidentally identified in 1994 by Schinkel, Smit (24), who found that a homozygous knockout of $A B C B 1$ in laboratory mice induced a 100 -fold increase in susceptibility to antiparasitic medications (25).

In humans, $A B C B 1$ protein is encoded by the $A B C B 1$ gene. An update was published in 2011 to illustrate the role of $A B C B 1$ genetic polymorphisms, which accounts for more than 65 exon related single-nucleotide polymorphisms (SNPs) (26). These SNPs could be responsible for the differences in drug response and toxicity in several types of cancers (15). In brain, $A B C B 1$ is localized in the luminal membrane of ECs of the BBB (13). It has an essential role protecting the brain from a possible brain uptake of toxic molecules or metabolic substances with a wide range of known substrates including $\operatorname{TMZ}(27)$.

Schaich et al., investigated the role of three different SNPs of $A B C B 1$ in GBM patients treated with TMZ. He showed that the rs1128503 SNP in MDR1 exon 12 is an independent predictive biomarker of response to TMZ. Patients with GBM exhibiting the homozygous allele ( $\mathrm{C} / \mathrm{C}$ allele) have better survival compared to their heterozygous variant counterparts (28). However, more recently, another large clinical cohort analyzed the clinical impact of four SNPs variants (rs2229109, rs1128503, rs2032582 and rs 1045642) in patients with newly diagnosed GBM patients treated with the standard of care. They did not find any clinical value of the SNPs investigated in a large Swedish 
cohort, hence could not validate the results obtained from Schaich study (29). One pilot clinical trial tried to evaluate $A B C B 1$ protein among glioma patients. They measured the uptake of $\left({ }^{11} \mathrm{C}\right) \quad \mathrm{N}$-desmethyl-loperamide $\left(\left({ }^{11} \mathrm{C}\right) \mathrm{dLop}\right)$ using positron emission tomography (PET) imaging as a marker of $A B C B 1$ activity. The clinical study aimed to recruit ten patients, however, only two registered patients are available in the clinical trial database, suggesting that early termination of the trial was due to the lack of patients that fits the inclusion criteria of the study(30).

Several studies have investigated the role of $A B C B 1$ in the context of TMZ treatment in GBM preclinical models. $A B C B 1$ downregulation was associated with increased efficacy of TMZ in U87 cell lines $(31,32)$. Two recent studies showed that that downregulation of $A B C B 1$ also increases efficacy of $T M Z$ in vitro and in vivo in GBM preclinical models $(33,34)$. Furthermore, an in vivo study reported a higher concentration of irinotecan in the brain of Mdrla (-/-) mice versus wild-type when both exposed to the same dose of irinotecan (35). The antitumor efficacy of TMZ against three intracranial tumor GBM models was significantly enhanced when $A b c b 1 a / b$ and $A b c g 2$ were genetically deficient or pharmacologically inhibited $(27,36)$. ABCB1 expression can be altered by several compounds including carbonic anhydrase XII (CAXII), Bone morphogenetic protein 7 (BMP7) and $\operatorname{TMZ}(33,37,38)$. Tso et al found that BMP7 sensitizes GBM stem cells to clinically relevant doses of TMZ (33) while Riganti and Salaroglio have found that GBM exposure to TMZ downregulates the expression of $A B C B 1$ (37). A recent study showed that CAXII could also reduce $A B C B 1$ activity and sensitize GBM cells to TMZ (38). (Table ) summarizes the xenobiotic that alters the function of $A B C B 1, A B C G 2$ and $A B C C 1$ transporters in $G B M$.

\section{ABCC1 (MRP1)}

The multidrug resistance-associated protein 1 (MRP1) is encoded by the $A B C C 1$ gene. It was described for the first time by Cole, Bhardwaj (39). ABCC1 protein is a 180- 
$190 \mathrm{kDa}$ protein and is ubiquitously expressed in many tissues in humans. It is highly expressed in intestine, kidney and testis, while a lower expression is detected in the lung, colon and brain (40). $A B C C 1$ protein has a wide range of substrates including anticancer drugs tested in GBM cell lines. i.e. vinca alkaloids (vincristine and vinblastine) and topoisomerase inhibitors (mitoxantrone) $(41,42)$. Many genetic alterations were detected in $A B C C 1$ gene, and most of them are SNPs in non-coding sequences and introns. A complete list of all ABCC1 SNPs can be obtained from available public database accessible from the national center for biotechnology information.

In the literature, $A B C C 1$ inhibitors including KIAP -an anti-apoptotic proteinreduce $A B C C 1$ activity and sensitize U251 GBM cell line to TMZ (43). Two in vitro studies found that $A B C C 1$ inhibition sensitizes cells to vincristine and etoposide but not to TMZ (42). Furthermore, a study showed that MK571, an inhibitor of $A B C C 1$ and $A B C C 4$, increased the anti-tumor efficacy of vincristine and etoposide in primary GBM cell lines (21). On the other hand, the overexpression of both $A B C B 1$ and $A B C G 1$ in $G B M$ cell lines (U87 and U251) is associated with resistance to TMZ (44).

\section{ABCG2, Breast Cancer Resistance Protein (BCRP)}

The ABCG2 protein was the first MRP-associated protein to be discovered. This 72 kDa protein was first identified in 1998 after being cloned from a human breast cancer cell line, which led to its alias, BCRP (45). It is highly expressed in the small intestine, colon, rectum, placenta, and smooth muscles in humans while a lower expression is detected in adrenal and thyroid glands, lung and cerebral cortex (46). In isolated brain microvessels and cortex biopsies from 12 patients with epilepsy or glioma, the expression of $A B C G 2$ protein was 1.6 folds the expression of $A B C B 1$ (47). $A B C G 2$ protein is a $A B C$ half transporter, therefore it requires the dimerization of two NBDs to function as a drug efflux pump (48). Many SNPs were identified in the $A B C G 2$ gene. The 
frequency of SNPs in ABCG2 gene is highly variable among ethnic groups, potentially associated with heterogeneous drug responses among these groups (49)

In 2017, a study enrolling 50 caucasian GBM patients found a correlation between expression of 8 different proteins (ABCG2, XIAP, MGMT, MSH2, pATM, pTp53, pAKT, Nestin) including $A B C G 2$ and they reported a correlation between $A B C G 2$ and the poor prognosis among GBM patients treated with the TMZ (50). To study the role of ABCG2 protein in vitro, they used GBM stem cells (GSC) and noticed an enhanced efficacy of $T M Z$ following the inhibition of $A B C G 2$. Therefore, they considered $A B C G 2$ a promising therapeutic target in GBMs (50). However, another study reported that ABCG2 knockdown results in the upregulation of other drug transporters ( $A B C B 1$ and $A B C C 3$ ) when treated with $\mathrm{TMZ}(51)$, suggesting that there might compensate mechanisms between transporters.

Several studies reported the importance of $A B C G 2$ in drug response in GBM. An in vivo study reported that $A B C G 2$ knockout in mice is associated with a better overall survival compared to wild-type mice when treated with dasatinib, a Src inhibitor (52). Another study showed that melatonin enhanced ABCG2 promoter methylation and sensitized GBM cell lines to mitoxantrone, doxorubicin and TMZ (53). Consistently with this study, the overexpression of ABCG2 in human GBM cell lines is found to be associated with mitoxantrone resistance (54). It was also reported that dual knockout of $A B C B 1$ and $A B C G 2$ improves efficacy of TMZ therapy in spontaneous GBM mouse models (55). Finally, TMZ exposure, in U87 and T89G cells, was found to increase ABCB1 and $A B C G 2$ mRNA expression. Therefore, exposure to TMZ itself could modulate the levels of $A B C$ proteins and could induce TMZ resistance among patients (56).

\section{Clinical Value}

To date, several strategies are developed to overcome the $A B C$ transporters mediated MDR. These strategies are summarized in (Figure) and they vary from 
partial/complete inhibition to bypass approaches: (i) nanocarriers technologies, (ii) antibody-drug conjugates -ADC-, and (iii) ultrasound-mediated BBB opening (UMBO).

Using partial or complete inhibitors of $A B C$ transporters can be combined with their substrates to enhance their CNS penetration and anticancer activity. Variety of modulators were tested to suppress activity of efflux proteins mainly (ABCB1 and $A B C G 2$ ) and few were successful enough to reach clinical trials. In GBM, a limited number of clinical trials were initiated to modulate $A B C$ proteins. To date, these trials failed to show significant clinical benefit, which could be related to a few reasons. Firstly, the study design was not optimal i.e., in the early clinical trials, the patients were not stratified based on high expression of $A B C$ proteins, and a precise evaluation of the role of $A B C B 1$ and $A B C G 2$ transporters in patients could not conducted. Secondly, modulators of $A B C$ proteins could change the pharmacokinetics of other drugs reducing their anti-tumor properties. Thirdly, the dose that was selected to inhibit the $A B C$ protein was not sufficient or a higher dose could not be applied safely in patients.

The selection of cancer cell line is a crucial step in in vitro studies dedicated to GBM. Many commercial human cells lines are available for GBM. However, a study from our laboratory has tested $A B C$ proteins expression in GBM patient-derived cell lines (PDCL) and their parental tumors (57). The study showed that PDCLs recapitulated better $A B C$ gene expression pattern of human GBM compared to commercial cell lines and can thus be considered a better model to test the biology of $A B C$ proteins in GBM. In addition, we found that fetal bovine serum that is usually added to cell culture medium for commercial GBM cell lines modulates resistance to TMZ. Recently, a study highlighted the importance of using low passage number PDCL and serum-free medium when studying the role of $A B C$ transporters in vitro. The high passaging number of commercial GBM cell lines could change the expression level of $A B C$ protein and could lead to conclusions irrelevant to newly diagnosed human tumor (57-59). 
Furthermore, sophisticated strategies using nanocarriers (nanocapsules, liposomes, micelles, dendrimers) for $A B C$ protein substrates were developed to allow these substrates to enter via endocytosis, improving drug half-live and drug protection (60). One clinical study investigated pegylated liposomal doxorubicin's efficacy when administered with TMZ and radiotherapy in newly diagnosed GBM patients. This study showed that the pegylated liposomal doxorubicin form is safe and tolerable however, no meaningful efficacy was observed from either the prolongation of TMZ therapy or the addition of liposomal doxorubicin (NCT00944801) (61). Another study evaluated the safety and the pharmacokinetics of a liposomal form of irinotecan, the study confirmed the safety of liposomal form of irinotecan. However, the efficacy still under investigation (62). Therefore, the nanocarrier forms' utilisation could be effective tools in future clinical studies (60).

Another strategy consists in the use of antibody-drug conjugates (ADCs) against a variety of targets in GBM and this approach is currently under investigation (63). ADCs are a newly developed biopharmaceutical compounds that allow the targeting of tumour cells while sparing healthy cells. This method is based on the use of an antibody to carry the substrate when binding to its ligand. In 2017, a published clinical trial showed a promising efficacy of depatuxizumab mafodotin (ABT-414), an ADC specific for the activated form of EGFR to selectively deliver a cytotoxic, in epidermal growth factor receptor (EGFR)-amplified recurrent GBM patients with manageable adverse effects (64). Another clinical trial was designed to evaluate its efficacy in newly diagnosed GBM patients (NCT02573324).

Finally, UMBO was used in pre-clinical models to bypass BBB efflux transporters and increase the brain's penetration of a wide variety of therapeutics. Low-intensity pulsed ultrasound can be delivered to the brain to induce a safe oscillation of intravenously injected microbubbles within blood vessels (65). Oscillation of these 
microbubbles opens the BBB by reversibly disrupting the tight junctions between ECs. A range of drugs have been tested for use with UMBO for treating gliomas and include TMZ, carmustine, irinotecan, carboplatin, doxorubicin, and drug-loaded liposomes (7, 66). A new study showed that UMBO could decrease the expression of $A B C B 1$ protein in cerebral vessels without affecting the integrity of other proteins (67). UMBO has recently moved to clinical trials where its clinical safety was confirmed: Sonocloud-induced UMBO was found to be safe and tolerable among GBM patients (68). Two other phase 1 and phase 2 clinical trials are currently in progress to evaluate UMBO's efficacy in combination with carboplatin in patients with recurrent GBM (NCT03744026).

\section{Conclusion}

GBM is an aggressive primary brain tumour with dismal prognosis. Over the last 15 years, no new drugs were found to be superior to TMZ. The long-term limited efficacy of TMZ is explained, at least partly, by the effect of MDR proteins $(A B C B, A B C C 1$ and $A B C G 2)$. Accumulating evidence are rising to connect the effect of chemotherapies and $A B C$ proteins. The clinical role of $A B C$ proteins is still under investigation and the failure of previous clinical trials raised several questions regarding the strategies to overcome MDR in GBM. A few clinical recommendations are currently being reported in the literature regarding future clinical trials. Firstly, all drugs that are going to be used in the trials should be tested against the major $A B C$ proteins $(A B C B, A B C C 1$ and $A B C G 2) . A$ wide range of in vitro and in vivo models could allow a precise testing of the novel drugs (58). Secondly, newly available non-invasive diagnostic imaging approaches i.e. PET scanning have the potential to determine whether $A B C B 1$ or other transporters are functioning to reduce drug accumulation and whether inhibition can change drug uptake in solid tumours $(69,70)$. Furthermore, dual $A B C$ inhibitors with a high specificity could be developed. Indeed, for example, the ABCB1 specific inhibitor zosuquidar enhanced sunitinib brain concentration in mice, but not to the same level as the dual 
inhibitions of $A B C B 1$ and $A B C G 2$ (71). Following these recommendations could lead to the design of clinical trials that might successfully demonstrate the therapeutic potential of $A B C$ protein inhibition in GBM treatment.

\section{Acknowledgments}

This work was supported by the European Union's Horizon 2020 research and innovation program under the Marie Skłodowska-Curie grant agreement \#766069 (GLIO-TRAIN). We would like to acknowledge the online BioRender platform that provided all the tools and icons to draw the manuscript's graphs.

The research leading to these results has received funding from the program Investissements d'avenir" ANR-10-IAIHU-06. Institut Universitaire de Cancérologie. INCA-DGOS-Inserm_12560 (SiRIC CURAMUS) benefits from support from Institut National du Cancer, ministère des Solidarités et de la Santé and Inserm.

\section{Authors' contributions}


MA performed the literature analysis, drawing of the figures, writing of the manuscript and final approval of the final version. AI participated in the original concept of the article, reviewing, and editing of the figures, reviewing the manuscript and final approval of the manuscript. MV and XD participated in reviewing the figures, reviewing the manuscript and final approval of the manuscript.

\section{Conflicts of interest}

No potential conflicts of interest were disclosed

AI reports grants and travel funding from Carthera (September 2019), research grants from Transgene, research grants from Sanofi, research grants from Air Liquide, travel funding from Leo Pharma 
Table 1: Analysis of published studies that show the effects of ABC transporters on chemotherapeutic agents used in GBM.

\begin{tabular}{|c|c|c|c|}
\hline Effect & $\begin{array}{l}\text { ABC Transporter } \\
\text { involved }\end{array}$ & $\begin{array}{l}\text { Drug } \\
\text { involved }\end{array}$ & Reference \\
\hline $\begin{array}{l}\text { High dose of cyclosporine }{ }^{1} \text { doubles the plasma concentration of etoposide among glioma } \\
\text { patients }\end{array}$ & ABCB1 & Cyclosporine & $(72)$ \\
\hline $\begin{array}{l}\text { Nimodipine } e^{2} \text { enhances sensitivity to procarbazine in viability tests in vitro using PDCLs } \\
\text { obtained from glioblastoma patients }\end{array}$ & $A B C B 1$ and $A B C G 2$ & Nimodipine & $(73)$ \\
\hline $\begin{array}{l}\text { Vincristine exposure induces an elevated expression of } A B C G 1 \text { in rats' brain. This effect } \\
\text { could lead to the assumption that } A B C B 1 \text { is partially responsible for the observed } \\
\text { resistance of a relapsing tumours. }\end{array}$ & ABCB1 & Vincristine & $(75)$ \\
\hline $\begin{array}{l}\text { Overexpression of ABCG2 in human GBM cell lines is associated with mitoxantrone } \\
\text { resistance. }\end{array}$ & ABCG2 & Mitoxantrone & $(54)$ \\
\hline $\begin{array}{l}\text { GBM cell lines overexpressing } A B C B 1 \text { exhibit high resistance to carmustine, carboplatin } \\
\text { and etoposide }\end{array}$ & ABCB1 & $\begin{array}{l}\text { Carmustine, } \\
\text { carboplatin } \\
\text { and } \\
\text { Etoposide }\end{array}$ & $(76)$ \\
\hline $\begin{array}{l}\text { Elacridar }{ }^{4} \text { sensitizes GBM cell lines to dasatinib. Homozygous knockout of ABCG2 in mice } \\
\text { results in a better overall survival compared to the wild type when treated with dasatininb }\end{array}$ & $A B C B 1$ and $A B C G 2$ & Elacridar & $(52)$ \\
\hline
\end{tabular}


Similar brain-to-plasma concentration was observed for sunitinib in both $A B C B 1$ and $A B C G 2$ knockout mice model and with elacridar treatment in mice. However, mild effect was observed with the zosuquidar ${ }^{5}$ and no effect with $\mathrm{KO} 143^{6}$

Inhibition of $A B C B 1$ and $A B C G 2$ with $A B T-888$ improves the efficacy of TMZ therapy in GBM patients.

Mdr1-/- mice show a higher concentration of irinotecan compared to mdrla+/+ mice when both exposed to the same dose of irinotecan.

MRP1 inhibition enhanced Vincristine and Etoposide but not TMZ chemotherapeutic effect however the combined inhibition of MRP1 and P glycoprotein (P-gp) using Reversan ${ }^{7}$ increased TMZ response in GBM PDCLs

Inhibition of $A B C B 1$ and $A B C G 2$ with verapamil and KO143 increases the efficacy of TMZ when combined with MGMT inhibitors.

Melatonin enhances ABCG2 promoter methylation hence sensitizes GBM cell lines to mitoxantrone, doxorubicin, TMZ

Limited drug delivery into brain tumors may significantly limit the efficacy of rucaparib ${ }^{8}$ combined with TMZ in GBM

$A Z D 2461^{9}$ has a limited brain permeability in vivo due to its efflux by $A B C B 1$ protein.

Downregulation of $A B C B 1$ and $A B C G 2$ by Bone morphogenetic protein 7 sanitize the $G B M$ stem cells to the clinically relevant dose of TMZ.

ABCE1 downregulation enhance the efficacy of TMZ in GBM cells (U87 and A172). $A B C G 2$ knockdown in several GBM cell lines resulted in upregulation of other drug transporters $A B C B 1$ and $A B C C 3$ when treated with $T M Z$.

KIAP -anti apoptotic protein- sensitizes U251 cells to TMZ through reduction of the ABCC1 expression

The study was not conclusive. Only $7 \%$ of the 125 cases studied showed detectable MDR1 expression, suggesting that $A B C B 1$ was not a major contributor to drug resistance in the selected cohort
Elacridar,

ABCB1 and ABCG2 KO143 and

Zosuquindar

ABCB1 and ABCG2 ABT-888

\begin{tabular}{l|l} 
ABCB1 Irinotecan &
\end{tabular}

\begin{tabular}{l|l} 
ABCC1 & $\begin{array}{l}\text { MK571 and } \\
\text { Etoposide }\end{array}$
\end{tabular}

ABCB1 and ABCG2 Verapamil

ABCG2 and $\mathrm{KO} 143$

ABCG2 Melatonin

ABCB1 and ABCG2 Rucaparib

\begin{tabular}{|l|l|} 
ABCB1 & AZD2461
\end{tabular}

ABCB1 and ABCG2 BMP7

ABCE1

TMZ

ABCG2

TMZ.

ABCC1

TMZ

(43)

ABCB1

TMZ

(79) 


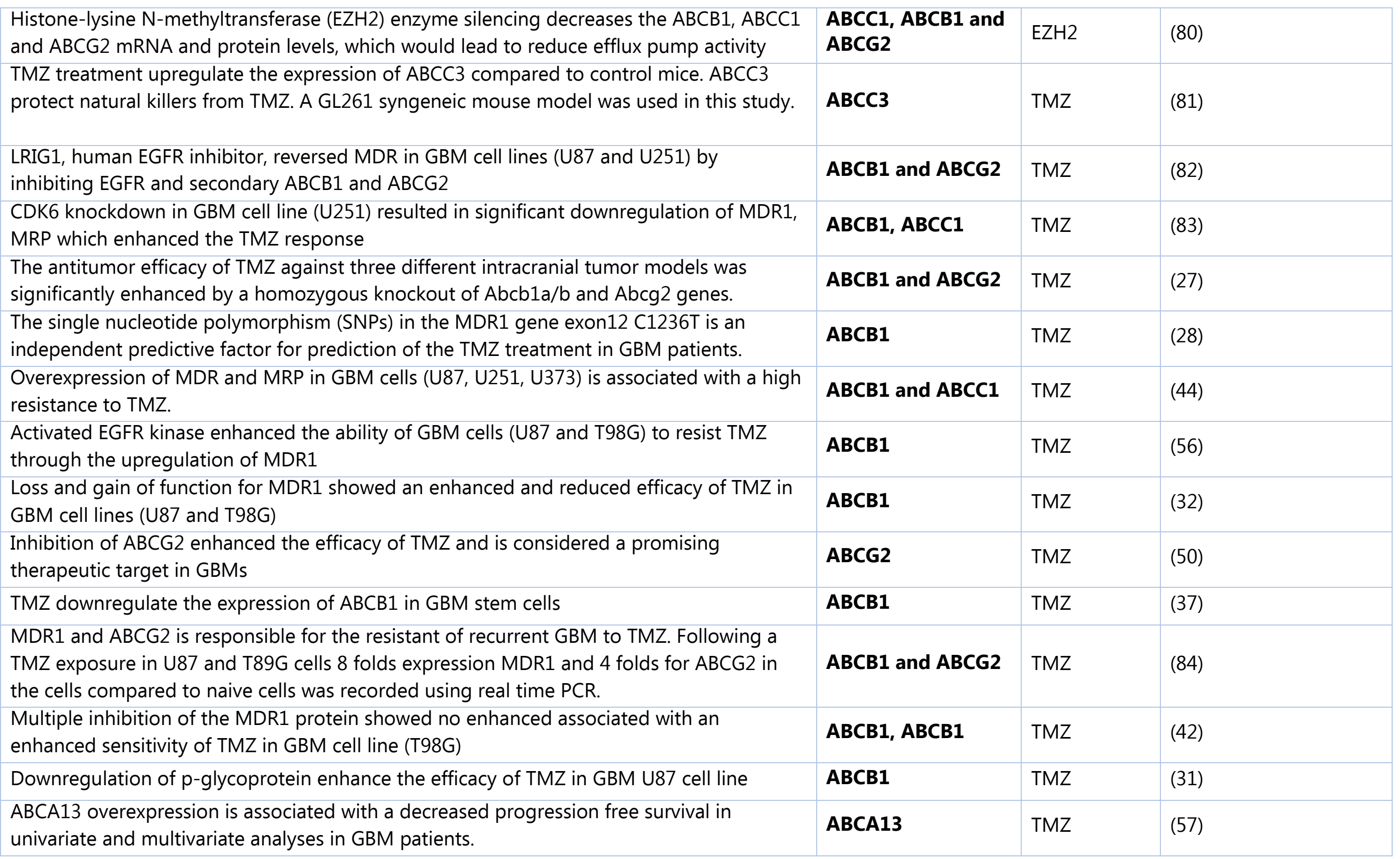


1 Immunosuppressant medication with ABCB1 blocking activity

${ }_{3}^{2}$ Calcium channel blockers with $A B C B 1$ blocking activity

3 An experimental cancer drug with $A B C B 1$ inhibition properties. It is a derivative of cyclosporine.

4 An experimental small molecule that has a dual $A B C B 1$ and $A B C G 2$ inhibition
5 potent $A B C B 1$ inhibitor, has reached clinical trials.

${ }_{7}^{6}$ Experimental drugs with $A B C G 2$ inhibition activity.

7 It is an experimental drug with $A B C C 1$ and $A B C B 1$ inhibition.

Poly (ADP ribose) polymerase (PARP) inhibitors

Table 2: Identified subfamilies of $A B C$ transporters and their physiological functions. 


\begin{tabular}{|c|c|c|c|}
\hline ABCA & 12 & $\begin{array}{l}\text { - Lipid and cholesterol transport, ABCA2 is involved in drug } \\
\text { resistance }\end{array}$ & (20) \\
\hline ABCB & 11 & $\begin{array}{l}\text { - Elimination of toxins } \\
\text { - Inhibition of apoptosis } \\
\text { - Volume dependent } \mathrm{Cl}^{-} \text {channel regulator } \\
\text { - Phospholipid translocation (can translocate short-chain } \\
\text { - } \text { Mhospholipids) } \\
\text { - } \text { esterification } \\
\text { - Drug resistance }\end{array}$ & $(20,85)$ \\
\hline ABCC & 13 & $\begin{array}{l}\text { - } \text { Anion efflux. } \\
\text { - } \text { Drug resistance } \\
\text { - } \text { Nucleoside transport }\end{array}$ & (20) \\
\hline ABCD & 4 & $\begin{array}{l}\text { - Mainly expressed in peroxisomes. } \\
\text { - } A B C D 2 \text { fatty acid transport and a major modifier locus for } \\
\text { clinical diversity in X-linked ALD }\end{array}$ & $(20)$ \\
\hline ABCE/ABCF & $\begin{array}{l}1 \mathrm{ABCE} \\
3 \mathrm{ABCF}\end{array}$ & $\begin{array}{l}\text { - Along with } A B C E 1, A B C F \text { members have ATP-binding } \\
\text { domains, but no transmembrane domains, making } \\
\text { transporter function unlikely } \\
\text { - Mainly regulate protein synthesis or expression }\end{array}$ & $(20)$ \\
\hline ABCG & 5 & $\begin{array}{l}\text { - Transport of diverse drug substrates, sterols, and lipids } \\
\text { - } A B C G 4 \text { is expressed in macrophages } \\
\text { - Drug resistance }\end{array}$ & (20) \\
\hline
\end{tabular}



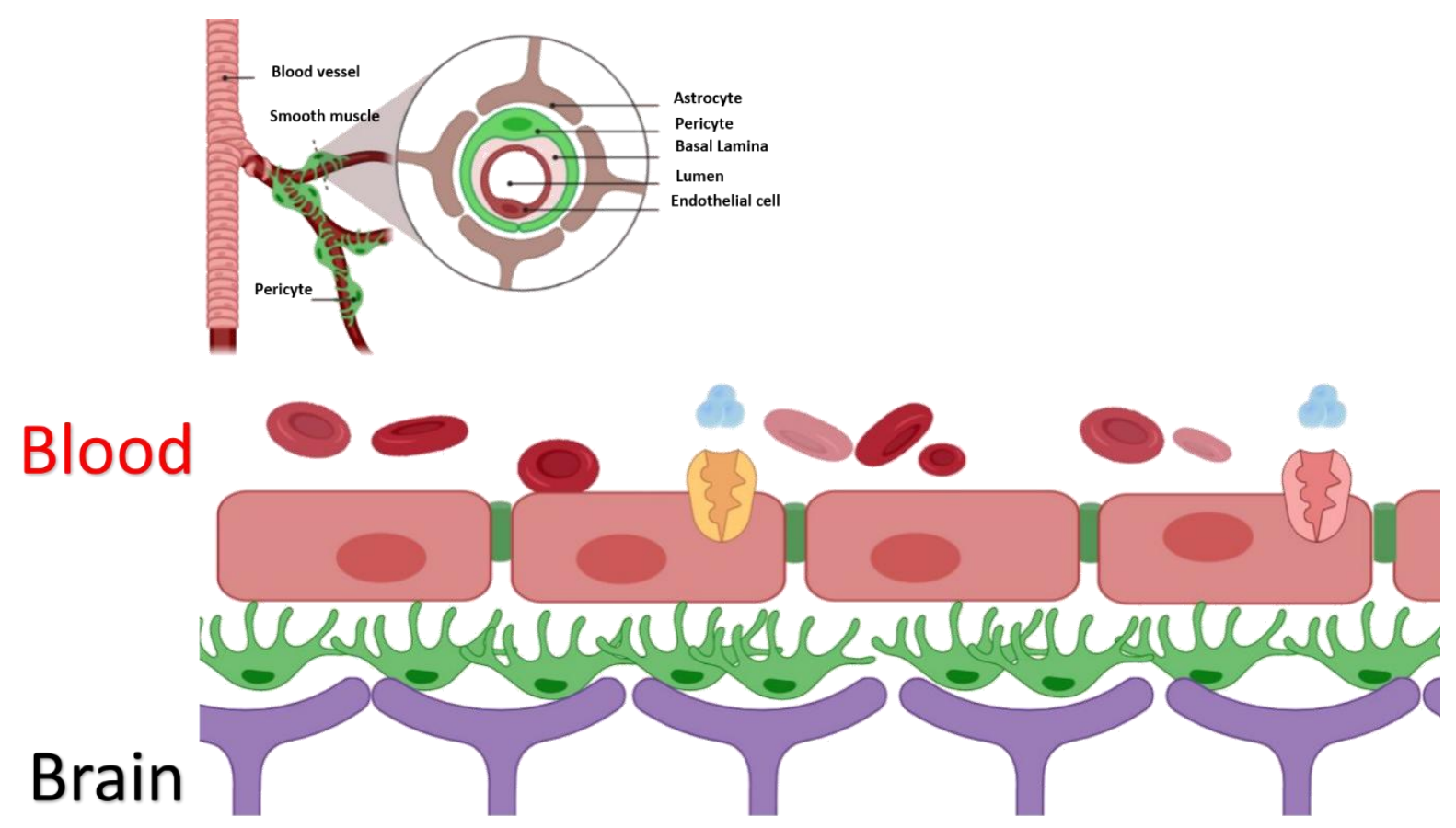

Figure 1: The blood-brain barrier (BBB) is formed of different types of cells tightly knit together. Highly specialized endothelial cells (ECs) surround blood vessels and form part of the BBB. In addition to brain ECs various cells contribute to the structure of BBB. Pericytes (represented in green) are attached to endothelium cells via gap junctions whilst astrocytes end feet (represented in purple) surround endothelial cells of the BBB, providing structural and functional support to these cells. Five mechanisms are known to regulate the entry of molecules to the brain. The efflux pumps pathway is considered a mechanism of active transport through the BBB (7). 


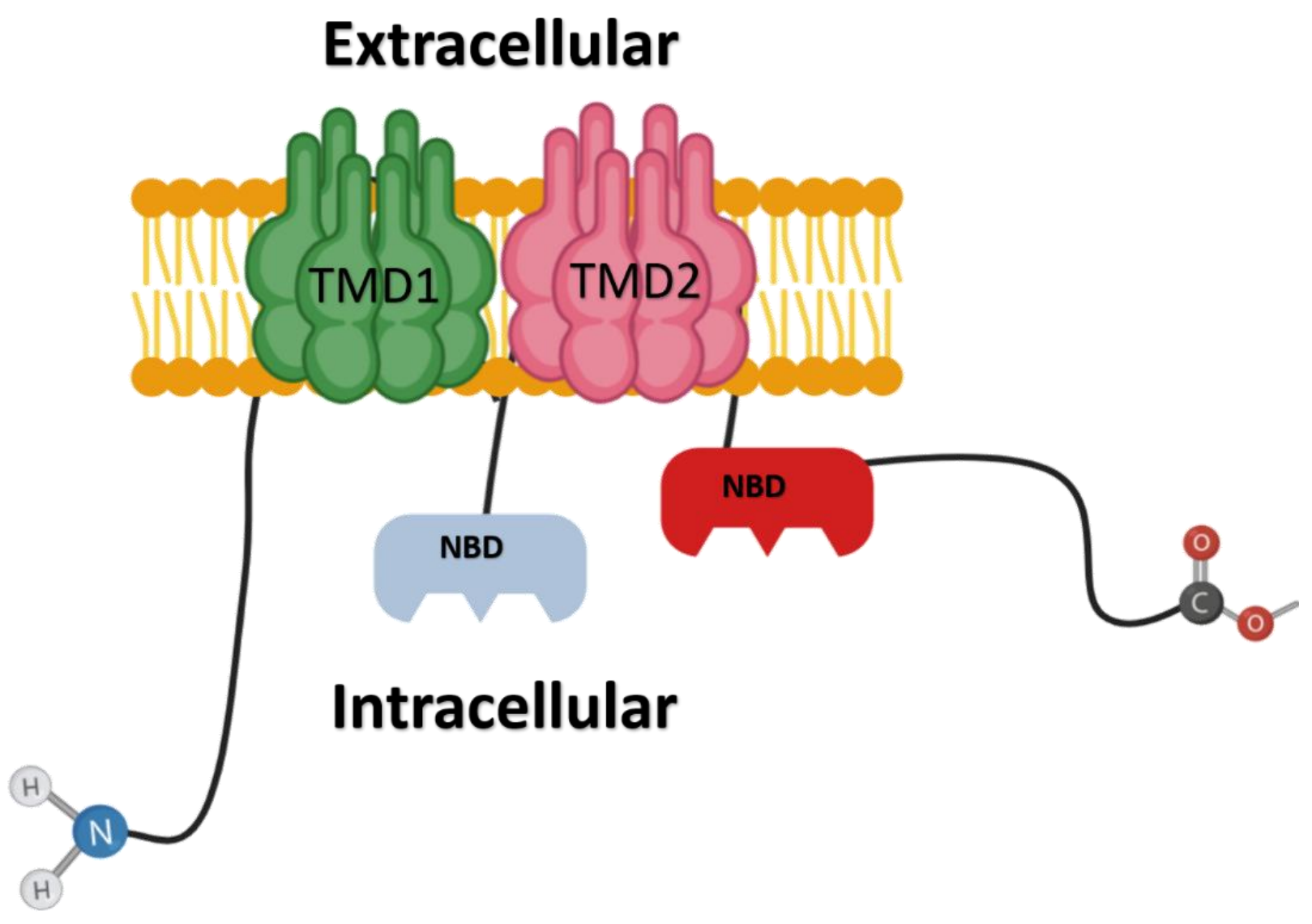

Figure 2: A full $A B C$ transporter consists of four building units. The first two building units called TMDs are formed by six transmembrane segments. TMD1 and TMD2 are colored in green and pale red, respectively. The two other building units are called NBDs, NBD1 (pale blue) and NBD2 (red). ABC half transporters have only one TMD and one NBD and need to dimerize to become a functional protein. Additionally, some other $A B C$ transporters have an additional TMD unit that is conjugated to the N-terminus of the protein and called "Long" $A B C$ transporter (86). 


\section{Extracellular}

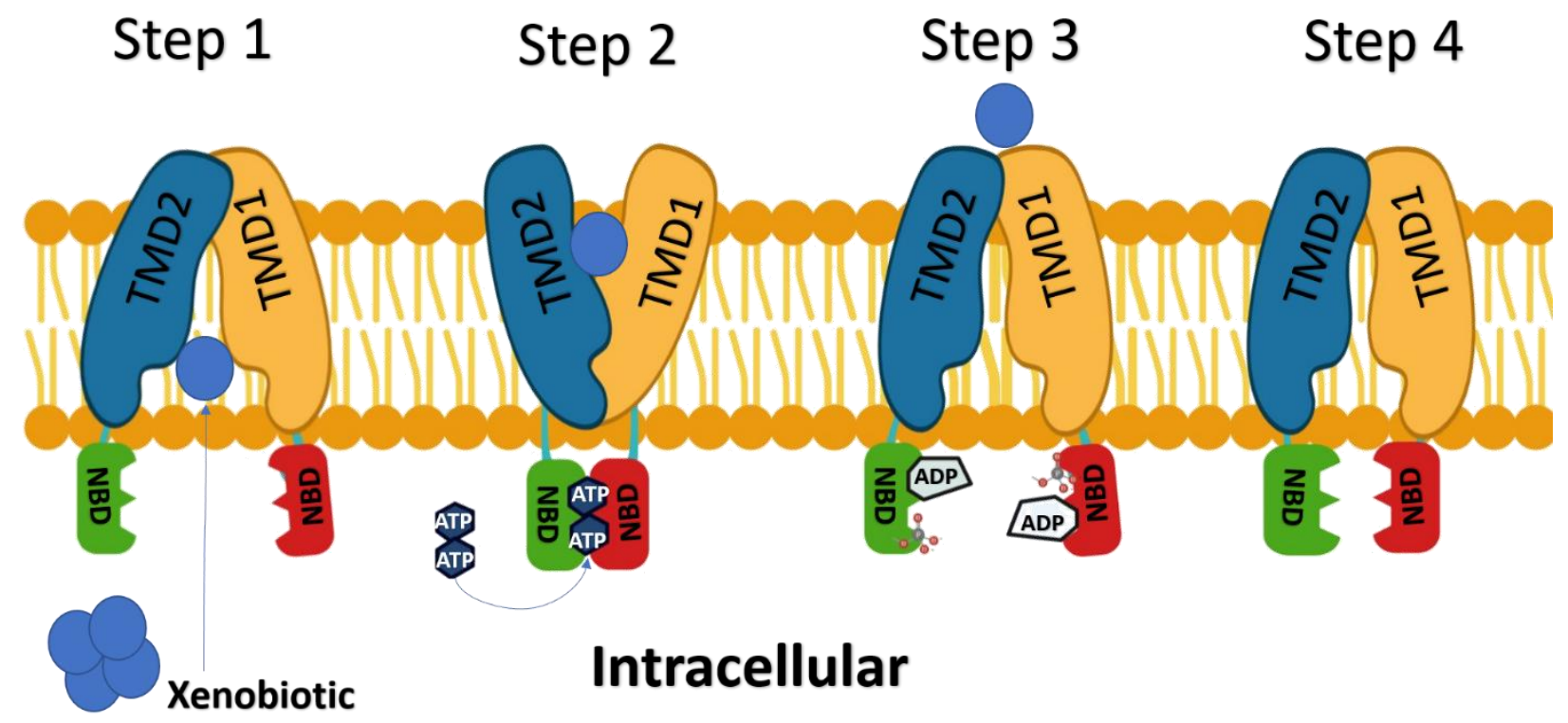

Figure 2: $A B C$ transporters are transmembrane proteins capable of actively transporting a xenobiotic from the intracellular to the extracellular compartments. This active transport requires the hydrolysis of ATP to provide the energy necessary for the transport. The active transport cycle starts with the binding of the xenobiotic to a high-affinity structure formed by the TMDs (step 1). As a result, a conformational change makes the NBD units more exposed for ATP binding. The NBD dimer induces a major conformational change on the TMDs allowing the xenobiotic to be translocated (step 2). The hydrolysis of ATP allows the NBD dimers to be dissociated and again induces a TMDs conformational change (step 3). A final step of restoration of the open NBD-dimer conformation then takes place (step 4) (14, 18). 


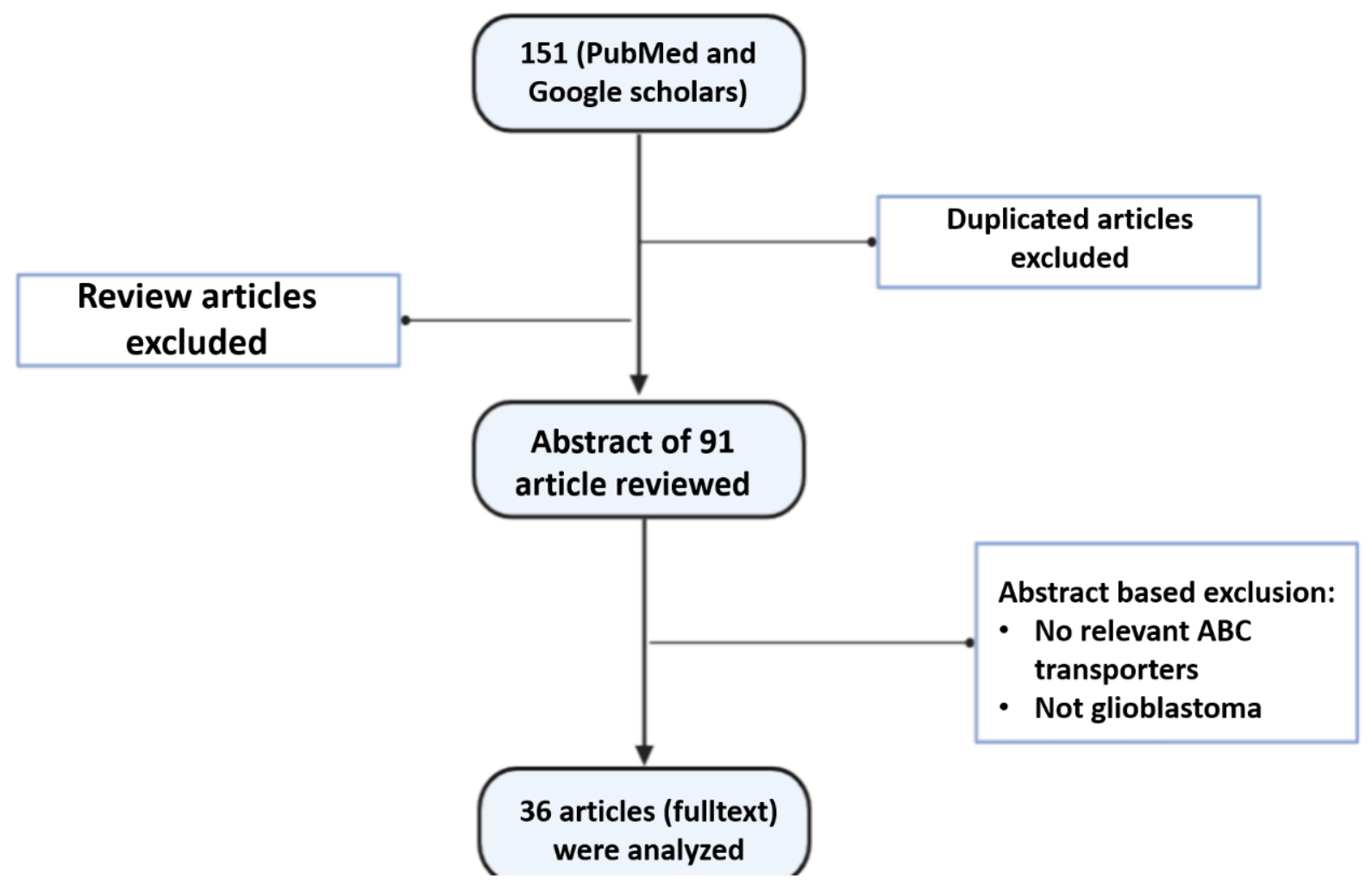

Figure 4: Represents the methodology of this literature review. The key words ( $A B C$ transporters, glioblastoma, $\mathrm{TMZ}$, and chemotherapy) were used in PubMed and Google scholar search engines. 151 articles appeared in the results, then a few steps were carried out to exclude the duplicated and review articles. 91 abstracts were then reviewed and from the abstract, only articles that studied ABC transporters or GBM were selected. Full texts were obtained for all 36 selected articles. 


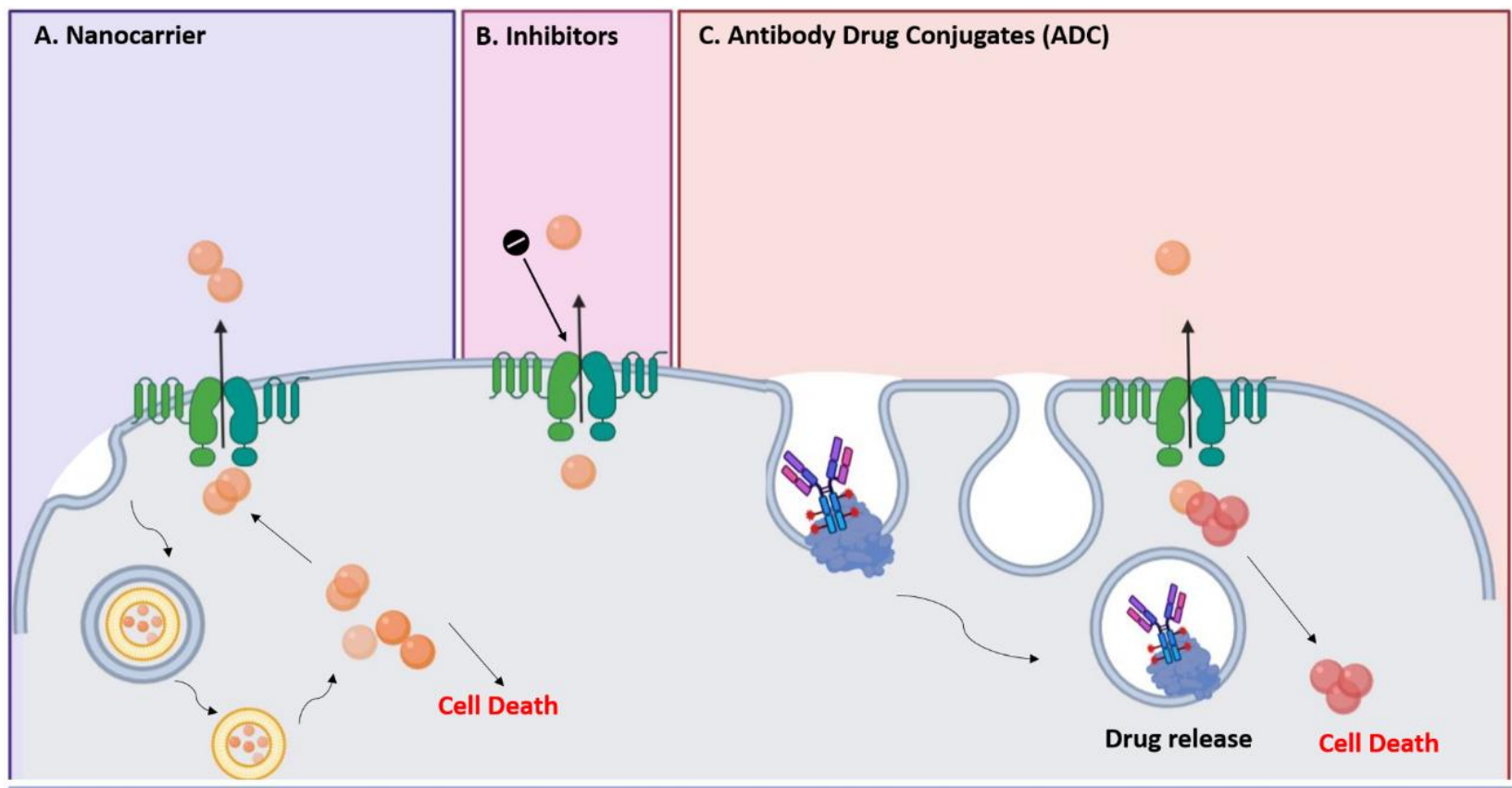

\section{Ultrasound mediated blood brain barrier opening}
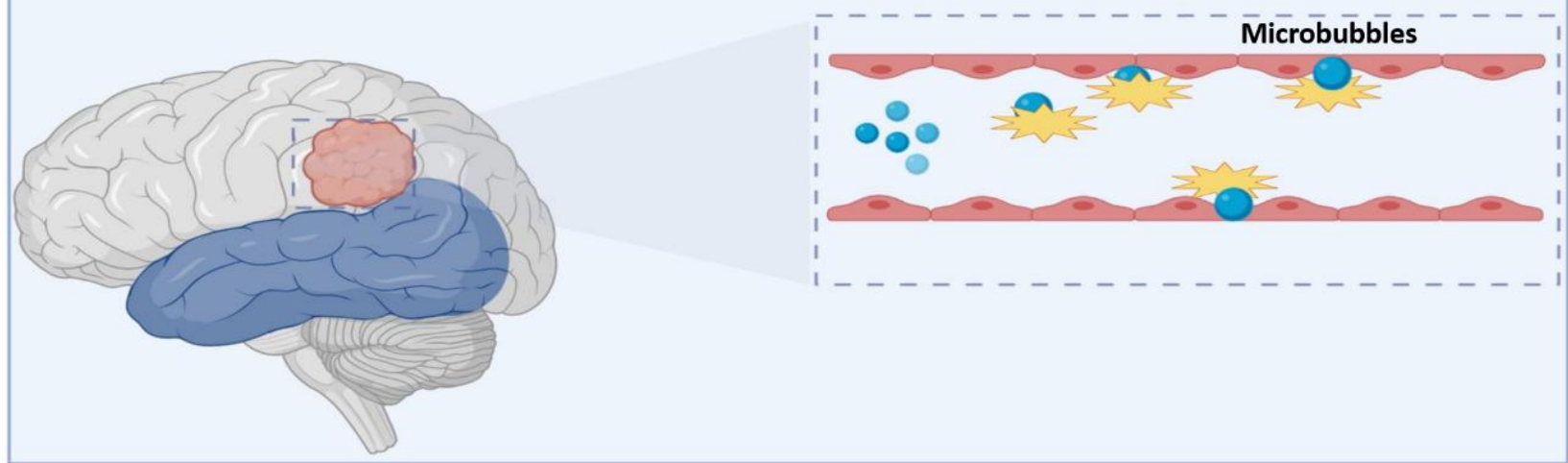

Figure 5: Summary of methods that are being developed to overcome $A B C$ transporters. Panel $A$ : represent the development of nanocarriers that allow the drug to enter via endocytosis. Panel B shows another method by using a partial or complete antagonist that can be administered in combination with the efflux pumps substrates and as a result enhance the activity of the substrates. Panel $C$ shows the antibody drug conjugates approach that relies on an antibody to carry the substrates when binding to its ligand. Panel $D$ represents the combined effect of using microbubbles and low intensity ultrasound to open the BBB. These four methods have been used in vitro and in vivo to develop strategies to overcome $A B C$ efflux pumps (87). 
References:

1. Ostrom QT, Gittleman H, Liao P, et al. CBTRUS Statistical Report: Primary brain and other central nervous system tumors diagnosed in the United States in 2010-2014. Neuro-oncology. 2017;19(suppl_5):v1-v88.

2. Pace A, Dirven L, Koekkoek JAF, et al. European Association for Neuro-Oncology (EANO) guidelines for palliative care in adults with glioma. The Lancet Oncology. 2017;18(6):e330-e40.

3. Information NCfB. Temozolomide. 2020 [cited 2020 Feb. 6]; Available from: https://pubchem.ncbi.nlm.nih.gov/compound/Temozolomide

4. Saunders NR, Dreifuss JJ, Dziegielewska KM, et al. The rights and wrongs of blood-brain barrier permeability studies: a walk through 100 years of history. Frontiers in neuroscience. 2014;8:404.

5. Shen S, Zhang W. ABC transporters and drug efflux at the blood-brain barrier. Reviews in the neurosciences. 2010;21(1):29-53.

6. Chaves C, Shawahna R, Jacob A, Scherrmann JM, Decleves X. Human ABC transporters at blood-CNS interfaces as determinants of CNS drug penetration. Current pharmaceutical design. 2014;20(10):1450-62.

7. Drean A, Goldwirt L, Verreault M, et al. Blood-brain barrier, cytotoxic chemotherapies and glioblastoma. Expert review of neurotherapeutics. 2016;16(11):1285-300.

8. Gillet JP, Gottesman MM. Mechanisms of multidrug resistance in cancer. Methods in molecular biology (Clifton, NJ). 2010;596:47-76.

9. Ramirez YP, Weatherbee JL, Wheelhouse RT, Ross AH. Glioblastoma multiforme therapy and mechanisms of resistance. Pharmaceuticals (Basel, Switzerland). 2013;6(12):1475-506.

10. Franceschi $\mathrm{E}$, Lamberti $\mathrm{G}$, Visani $\mathrm{M}$, et al. Temozolomide rechallenge in recurrent glioblastoma: when is it useful? Future oncology (London, England). 2018;14(11):1063-9.

11. Turk D, Hall MD, Chu BF, et al. Identification of compounds selectively killing multidrugresistant cancer cells. Cancer research. 2009;69(21):8293-301.

12. Drean A, Rosenberg S, Lejeune FX, et al. Correction to: ATP binding cassette (ABC) transporters: expression and clinical value in glioblastoma. Journal of neuro-oncology. 2018;138(3):487.

13. Mahringer A, Fricker G. ABC transporters at the blood-brain barrier. Expert opinion on drug metabolism \& toxicology. 2016;12(5):499-508.

14. Linton KJ, Higgins CF. Structure and function of $A B C$ transporters: the ATP switch provides flexible control. Pflugers Archiv : European journal of physiology. 2007;453(5):555-67.

15. Lockhart AC, Tirona RG, Kim RB. Pharmacogenetics of ATP-binding cassette transporters in cancer and chemotherapy. Molecular cancer therapeutics. 2003;2(7):685-98.

16. Schinkel AH, Jonker JW. Mammalian drug efflux transporters of the ATP binding cassette (ABC) family: an overview. Advanced drug delivery reviews. 2003;55(1):3-29.

17. Pulgar VM. Transcytosis to Cross the Blood Brain Barrier, New Advancements and Challenges. Frontiers in neuroscience. 2018;12:1019.

18. Zolnerciks JK, Andress EJ, Nicolaou M, Linton KJ. Structure of ABC transporters. Essays in biochemistry. 2011;50(1):43-61.

19. Raymond GV, Moser AB, Fatemi A. X-Linked Adrenoleukodystrophy. 1999 Mar 26 [Updated 2018 Feb 15]. In: Adam MP, Ardinger HH, Pagon RA, et al., editors. GeneReviews ${ }^{\circledR}$ [Internet]. Seattle (WA): University of Washington, Seattle; 1993-2020. Bookshelf URL:

https://www.ncbi.nlm.nih.gov/books/.

20. Vasiliou V, Vasiliou K, Nebert DW. Human ATP-binding cassette (ABC) transporter family. Human genomics. 2009;3(3):281-90. 
21. Tivnan A, Zakaria Z, O'Leary C, et al. Inhibition of multidrug resistance protein 1 (MRP1) improves chemotherapy drug response in primary and recurrent glioblastoma multiforme. Frontiers in neuroscience. 2015;9:218.

22. Juliano RL, Ling V. A surface glycoprotein modulating drug permeability in Chinese hamster ovary cell mutants. Biochimica et biophysica acta. 1976;455(1):152-62.

23. Atlas THP. The Human Protein Atlas 2020 Feb, 6 [cited; Available from: https://www.proteinatlas.org/ENSG00000085563-ABCB1/tissue

24. Schinkel AH, Smit JJ, van Tellingen O, et al. Disruption of the mouse mdr1a P-glycoprotein gene leads to a deficiency in the blood-brain barrier and to increased sensitivity to drugs. Cell. 1994;77(4):491-502.

25. Borst $\mathrm{P}$, Schinkel AH. P-glycoprotein $A B C B 1$ : a major player in drug handling by mammals. The Journal of clinical investigation. 2013;123(10):4131-3.

26. Wolf SJ, Bachtiar M, Wang J, Sim TS, Chong SS, Lee CG. An update on ABCB1 pharmacogenetics: insights from a 3D model into the location and evolutionary conservation of residues corresponding to SNPs associated with drug pharmacokinetics. The pharmacogenomics journal. 2011;11(5):315-25.

27. de Gooijer MC, de Vries NA, Buckle T, et al. Improved Brain Penetration and Antitumor Efficacy of Temozolomide by Inhibition of ABCB1 and ABCG2. Neoplasia. 2018;20(7):710-20.

28. Schaich $M$, Kestel L, Pfirrmann M, et al. A MDR1 (ABCB1) gene single nucleotide polymorphism predicts outcome of temozolomide treatment in glioblastoma patients. Annals of oncology : official journal of the European Society for Medical Oncology. 2009;20(1):175-81.

29. Malmstrom A, Lysiak M. ABCB1 single-nucleotide variants and survival in patients with glioblastoma treated with radiotherapy concomitant with temozolomide. 2019.

30. (11C)dLop as a Marker of P-Glycoprotein Function in Patients With Gliomas. [cited; Available from:

https://clinicaltrials.gov/ct2/show/NCT01281982?id=NCT01281982\&draw=2\&rank=1\&load=cart

31. Zhang Y, Wang SX, Ma JW, et al. EGCG inhibits properties of glioma stem-like cells and synergizes with temozolomide through downregulation of P-glycoprotein inhibition. Journal of neuro-oncology. 2015;121(1):41-52.

32. Munoz JL, Walker ND, Scotto KW, Rameshwar P. Temozolomide competes for P-glycoprotein and contributes to chemoresistance in glioblastoma cells. Cancer letters. 2015;367(1):69-75.

33. Tso JL, Yang S, Menjivar JC, et al. Bone morphogenetic protein 7 sensitizes O6-

methylguanine methyltransferase expressing-glioblastoma stem cells to clinically relevant dose of temozolomide. Molecular cancer. 2015;14:189.

34. Zhang $P$, Chen $X B$. Down-regulation of $A B C E 1$ inhibits temozolomide resistance in glioma through the PI3K/Akt/NF-kappaB signaling pathway. 2018;38(6).

35. Goldwirt L, Beccaria K, Carpentier A, Farinotti R, Fernandez C. Irinotecan and temozolomide brain distribution: a focus on ABCB1. Cancer chemotherapy and pharmacology. 2014;74(1):185-93.

36. de Gooijer MC, Buil LCM, Citirikkaya CH, Hermans J, Beijnen JH, van Tellingen O. ABCB1

Attenuates the Brain Penetration of the PARP Inhibitor AZD2461. Molecular pharmaceutics. 2018;15(11):5236-43.

37. Riganti C, Salaroglio IC, Caldera V, et al. Temozolomide downregulates P-glycoprotein expression in glioblastoma stem cells by interfering with the Wnt3a/glycogen synthase-3 kinase/beta-catenin pathway. Neuro-oncology. 2013;15(11):1502-17.

38. Salaroglio IC, Mujumdar P, Annovazzi L, et al. Carbonic Anhydrase XII Inhibitors Overcome PGlycoprotein-Mediated Resistance to Temozolomide in Glioblastoma. Molecular cancer therapeutics. 2018;17(12):2598-609.

39. Cole SP, Bhardwaj G, Gerlach JH, et al. Overexpression of a transporter gene in a multidrugresistant human lung cancer cell line. Science. 1992;258(5088):1650-4.

40. Uhlen M, Fagerberg L, Hallstrom BM, et al. Proteomics. Tissue-based map of the human proteome. Science. 2015;347(6220):1260419. 
41. Yin J, Zhang J. Multidrug resistance-associated protein 1 (MRP1/ABCC1) polymorphism: from discovery to clinical application. Zhong nan da xue xue bao Yi xue ban = Journal of Central South University Medical sciences. 2011;36(10):927-38.

42. Peignan L, Garrido W, Segura R, et al. Combined use of anticancer drugs and an inhibitor of multiple drug resistance-associated protein-1 increases sensitivity and decreases survival of glioblastoma multiforme cells in vitro. Neurochem Res. 2011;36(8):1397-406.

43. Liu $\mathrm{Y}$, Guo Q, Zhang $\mathrm{H}$, et al. Effect of siRNA-Livin on drug resistance to chemotherapy in glioma U251 cells and CD133(+) stem cells. Experimental and therapeutic medicine. 2015;10(4):1317-23.

44. Liang F, Wang B, Bao L, Zhao YS, Zhang SM, Zhang SQ. Overexpression of ILK promotes temozolomide resistance in glioma cells. Molecular medicine reports. 2017;15(3):1297-304.

45. Doyle LA, Yang W, Abruzzo LV, et al. A multidrug resistance transporter from human MCF-7 breast cancer cells. Proceedings of the National Academy of Sciences of the United States of America. 1998;95(26):15665-70.

46. Atlas HP. ABCG2 Human protein expression [cited; Available from:

https://www.proteinatlas.org/ENSG00000118777-ABCG2/tissue

47. Shawahna $R$, Uchida $Y$, Declèves $X$, et al. Transcriptomic and quantitative proteomic analysis of transporters and drug metabolizing enzymes in freshly isolated human brain microvessels.

Molecular pharmaceutics. 2011;8(4):1332-41.

48. Mao $Q$, Unadkat JD. Role of the breast cancer resistance protein (BCRP/ABCG2) in drug transport--an update. The AAPS journal. 2015;17(1):65-82.

49. Hira D, Terada T. BCRP/ABCG2 and high-alert medications: Biochemical, pharmacokinetic, pharmacogenetic, and clinical implications. Biochemical pharmacology. 2018;147:201-10.

50. Emery IF, Gopalan A, Wood S, et al. Expression and function of ABCG2 and XIAP in glioblastomas. Journal of neuro-oncology. 2017;133(1):47-57.

51. Chua C, Zaiden N, Chong KH, et al. Characterization of a side population of astrocytoma cells in response to temozolomide. Journal of neurosurgery. 2008;109(5):856-66.

52. Agarwal S, Mittapalli RK, Zellmer DM, et al. Active efflux of Dasatinib from the brain limits efficacy against murine glioblastoma: broad implications for the clinical use of molecularly targeted agents. Molecular cancer therapeutics. 2012;11(10):2183-92.

53. Martin V, Sanchez-Sanchez AM, Herrera F, et al. Melatonin-induced methylation of the ABCG2/BCRP promoter as a novel mechanism to overcome multidrug resistance in brain tumour stem cells. British journal of cancer. 2013;108(10):2005-12.

54. Rao VK, Wangsa $D$, Robey RW, et al. Characterization of ABCG2 gene amplification manifesting as extrachromosomal DNA in mitoxantrone-selected SF295 human glioblastoma cells. Cancer genetics and cytogenetics. 2005;160(2):126-33.

55. Lin F, de Gooijer MC, Roig EM, et al. ABCB1, ABCG2, and PTEN determine the response of glioblastoma to temozolomide and ABT-888 therapy. Clinical cancer research : an official journal of the American Association for Cancer Research. 2014;20(10):2703-13.

56. Munoz JL, Rodriguez-Cruz V, Greco SJ, Nagula V, Scotto KW, Rameshwar P. Temozolomide induces the production of epidermal growth factor to regulate MDR1 expression in glioblastoma cells. Molecular cancer therapeutics. 2014;13(10):2399-411.

57. Drean A, Rosenberg $S$, Lejeune FX, et al. ATP binding cassette (ABC) transporters: expression and clinical value in glioblastoma. Journal of neuro-oncology. 2018;138(3):479-86.

58. Tamaki A, lerano C, Szakacs G, Robey RW, Bates SE. The controversial role of ABC transporters in clinical oncology. Essays in biochemistry. 2011;50(1):209-32.

59. Leonard GD, Fojo T, Bates SE. The role of $A B C$ transporters in clinical practice. The oncologist. 2003;8(5):411-24.

60. Zhao M, van Straten D, Broekman MLD, Préat V, Schiffelers RM. Nanocarrier-based drug combination therapy for glioblastoma. Theranostics. 2020;10(3):1355-72. 
61. Beier CP, Schmid C, Gorlia T, et al. RNOP-09: pegylated liposomal doxorubicine and prolonged temozolomide in addition to radiotherapy in newly diagnosed glioblastoma--a phase II study. BMC cancer. 2009;9:308.

62. Clarke JL, Molinaro AM, DeSilva AA, et al. A phase I trial of intravenous liposomal irinotecan in patients with recurrent high-grade gliomas. Journal of Clinical Oncology. 2015;33(15_suppl):2029-. 63. Gan HK, van den Bent M, Lassman AB, Reardon DA, Scott AM. Antibody-drug conjugates in glioblastoma therapy: the right drugs to the right cells. Nature reviews Clinical oncology. 2017;14(11):695-707.

64. Reardon $D A$, Lassman $A B$, van den Bent $M$, et al. Efficacy and safety results of ABT-414 in combination with radiation and temozolomide in newly diagnosed glioblastoma. Neuro-oncology. 2017;19(7):965-75.

65. Hynynen K, McDannold N, Vykhodtseva N, Jolesz FA. Noninvasive MR imaging-guided focal opening of the blood-brain barrier in rabbits. Radiology. 2001;220(3):640-6.

66. Beccaria K, Canney M, Goldwirt L, et al. Ultrasound-induced opening of the blood-brain barrier to enhance temozolomide and irinotecan delivery: an experimental study in rabbits. Journal of neurosurgery. 2016;124(6):1602-10.

67. Choi H, Lee EH, Han M, An SH, Park J. Diminished Expression of P-glycoprotein Using Focused Ultrasound Is Associated With JNK-Dependent Signaling Pathway in Cerebral Blood Vessels. Frontiers in neuroscience. 2019;13:1350.

68. Idbaih A, Canney M, Belin L, et al. Safety and Feasibility of Repeated and Transient BloodBrain Barrier Disruption by Pulsed Ultrasound in Patients with Recurrent Glioblastoma. 2019;25(13):3793-801.

69. Fomichov V, Broholm H, Grunnet K, et al. The pharmacogenomics journal.

70. Bauer M, Romermann K, Karch R, et al. Pilot PET Study to Assess the Functional Interplay Between $A B C B 1$ and $A B C G 2$ at the Human Blood-Brain Barrier. Clinical pharmacology and therapeutics. 2016;100(2):131-41.

71. Oberoi RK, Mittapalli RK, Elmquist WF. Pharmacokinetic assessment of efflux transport in sunitinib distribution to the brain. The Journal of pharmacology and experimental therapeutics. 2013;347(3):755-64.

72. Lum BL, Kaubisch S, Yahanda AM, et al. Alteration of etoposide pharmacokinetics and pharmacodynamics by cyclosporine in a phase I trial to modulate multidrug resistance. Journal of clinical oncology : official journal of the American Society of Clinical Oncology. 1992;10(10):1635-42. 73. Durmaz R, Deliorman S, Uyar R, Isiksoy S, Erol K, Tel E. The effects of anticancer drugs in combination with nimodipine and verapamil on cultured cells of glioblastoma multiforme. Clinical neurology and neurosurgery. 1999;101(4):238-44.

74. Fellner S, Bauer B, Miller DS, et al. Transport of paclitaxel (Taxol) across the blood-brain barrier in vitro and in vivo. The Journal of clinical investigation. 2002;110(9):1309-18.

75. Balayssac D, Cayre A, Authier N, et al. Patterns of P-glycoprotein activity in the nervous system during vincristine-induced neuropathy in rats. Journal of the peripheral nervous system : JPNS. 2005;10(3):301-10.

76. Nakai E, Park K, Yawata T, et al. Enhanced MDR1 expression and chemoresistance of cancer stem cells derived from glioblastoma. Cancer investigation. 2009;27(9):901-8.

77. Tomaszowski KH, Schirrmacher R, Kaina B. Multidrug Efflux Pumps Attenuate the Effect of MGMT Inhibitors. Molecular pharmaceutics. 2015;12(11):3924-34.

78. Parrish KE, Cen L, Murray J, et al. Efficacy of PARP Inhibitor Rucaparib in Orthotopic Glioblastoma Xenografts Is Limited by Ineffective Drug Penetration into the Central Nervous System. Molecular cancer therapeutics. 2015;14(12):2735-43.

79. Fruehauf JP, Brem H, Brem S, et al. In vitro drug response and molecular markers associated with drug resistance in malignant gliomas. Clinical cancer research : an official journal of the American Association for Cancer Research. 2006;12(15):4523-32. 
80. Fan TY, Wang $\mathrm{H}$, Xiang $\mathrm{P}$, et al. Inhibition of EZH2 reverses chemotherapeutic drug TMZ chemosensitivity in glioblastoma. International journal of clinical and experimental pathology. 2014;7(10):6662-70.

81. Pessina S, Cantini G, Kapetis D, et al. The multidrug-resistance transporter Abcc3 protects NK cells from chemotherapy in a murine model of malignant glioma. Oncoimmunology. 2016;5(5):e1108513.

82. Liu B, Guo Z, Dong H, et al. LRIG1, human EGFR inhibitor, reverses multidrug resistance through modulation of $A B C B 1$ and ABCG2. Brain Res. 2015;1611:93-100.

83. Li B, He H, Tao BB, et al. Knockdown of CDK6 enhances glioma sensitivity to chemotherapy. Oncology reports. 2012;28(3):909-14.

84. Munoz JL, Rodriguez-Cruz V, Ramkissoon SH, Ligon KL, Greco SJ, Rameshwar P. Temozolomide resistance in glioblastoma occurs by miRNA-9-targeted PTCH1, independent of sonic hedgehog level. Oncotarget. 2015;6(2):1190-201.

85. Johnstone RW, Ruefli AA, Smyth MJ. Multiple physiological functions for multidrug transporter P-glycoprotein? Trends in biochemical sciences. 2000;25(1):1-6.

86. Deeley RG, Westlake C, Cole SP. Transmembrane transport of endo- and xenobiotics by mammalian ATP-binding cassette multidrug resistance proteins. Physiological reviews. 2006;86(3):849-99.

87. Li W, Zhang $\mathrm{H}$, Assaraf $Y$ G, et al. Overcoming ABC transporter-mediated multidrug resistance: Molecular mechanisms and novel therapeutic drug strategies. Drug resistance updates : reviews and commentaries in antimicrobial and anticancer chemotherapy. 2016;27:14-29. 